\title{
PRECEDENTES NORMATIVOS FORMALMENTE VINCULANTES: A FORMALIZAÇÃO DAS FONTES JURISPRUDENCIAIS*
}

\author{
Formally binding normative precedent: formalization \\ of jurisprudential sources
}

\author{
Hermes Zaneti Jr.** \\ Universidade Federal do Espírito Santo
}

Recepción: 23/09/2015

Aceptación: 29/4/2016

\section{Resumo}

Neste artigo o autor nos permite compreender o que o âmbito de aplicação do precedente legal no trabalho realizado pelo juiz e seu papel na reconstrução da resolução em conflito direita.

Palavras chave: Precedente formalmente vinculante; vinculatividade; jurisprudência persuasiva; jusnaturalismo; juspositivismo.

\section{Abstract}

In this article the author allows us to understand what is the scope of application of legal precedent in the work done by court and its role in the reconstruction of resolution in a direct conflict.

Keywords: Previous formally binding; vinculatividade; persuasive case law; natural law; positive law.

* Artículo basado en la ponencia dictada en el I Congreso Internacional de Derecho Procesal y Arbitraje, organizado por la Facultad de Derecho de la Universidad Continental, en la ciudad de Huancayo del 2 al 5 de setiembre de 2015.

** Doutor e Mestre em Direito Processual pela Universidade Federal do Rio Grande do Sul. Pós-doutorado na Università degli Studi di Torino. Doutor em Teoria do Direito e Filosofia do Direito pela Università degli Studi di Roma Tre. Professor Adjunto de Direito Processual Civil nos cursos de mestrado e graduação da Universidade Federal do Espírito Santo. Promotor de Justiça MPES. Versões preliminares deste ensaio foram remetidas para publicação Editora JusPodivm na coletânea «Precedentes» sobre os impactos do novo CPC e para o livro organizado pelo Prof. Rodrigo Mazzei, sobre a produção dos juristas «capixabas» no novo CPC. 


\section{A MUDANÇA PARADIGMÁTICA DO NOVO CPC. PRECE- DENTES COMO FONTE PRIMÁRIA NORMATIVA E FOR- MALMENTE VINCULANTE E A JURISPRUDÊNCIA COMO FONTE SECUNDÁRIA E PERSUASIVA}

Este texto procura demonstrar que o problema dos precedentes nos países de civil law ou híbridos não é mais um problema de convergência entre as tradições de civil law e common law, mas um problema de teoria do direito. Parte, portanto, da constatação que o direito regula também as suas próprias fontes e que do ponto de vista formal não é incongruente ou contraditório com o positivismo jurídico adotar um modelo de precedentes, especialmente se regulado expressamente em lei. $\bigcirc$ modelo de precedentes proposto parte assume que, do ponto de vista racional, é melhor vincular os juízes e tribunais à universalização de suas decisões, seja na formação, seja na aplicação dos precedentes judiciais. $\bigcirc$ Brasil, como já aconteceu nos processos coletivos, assume uma posição normativa de vanguarda nos ordenamentos jurídico da América Latina ao tratar do tema.

Os precedentes representam uma mudança paradigmática no CPC/2015 (Lei 13.105). Os precedentes vinculantes são, sem dúvida, uma das maiores mudanças da nova legislação. $\bigcirc$ direito anterior vinha aos poucos reconhecendo a jurisprudência com força normativa, mas era uma recepção mitigada do stare decisis - regra que, no common law, determina a vinculação dos juízes e tribunais ao que foi decidido anteriormente- nada comparado com as dimensões que a nova legislação processual apresenta agora. $\bigcirc$ direito brasileiro adotou, com a edição do novo Código de Processo Civil, um modelo normativo de precedentes formalmente vinculantes que passarão a constituir fonte primária no nosso ordenamento jurídico' .

A nova legislação reconhece, no art. 926, caput, o dever dos tribunais de manterem a sua jurisprudência (rectius: precedentes) estável, coerente e íntegra.

No art. 927 e incisos o legislador determina, aos juízes e aos tribunais, o dever de observância: a) das decisões do STF em controle de consti-

1 ZANETI JR., Hermes. O valor vinculante dos precedentes. Salvador: Jus Podivm, 2015. Como afirmou a doutrina: "O legislador brasileiro inequivocamente já havia importado, portanto, mesmo antes da promulgação do Novo CPC, a técnica do precedente vinculante ou obrigatório. Não trouxe com isso, porém, o mais importante, que é a técnica cuidadosa de se tomar em conta todas as circunstâncias do caso, ouvir atentamente os argumentos por analogia e diferenciação, justificar sua decisão em argumentos de princípio e argumentos consequencialistas e assegurar a igualdade das partes e a integridade de suas decisões». BUSTAMANTE, Thomas da Rosa de. A dificuldade de se criar uma cultura argumentativa do precedente judicial e o desafio do novo CPC, nesta coletânea. 
tucionalidade; b) dos enunciados da súmula vinculante; c) das decisões em assunção de competência e causas repetitivas (IRDR e REER); d) dos enunciados das súmulas do STF, em matéria constitucional, e do STJ, em matéria infraconstitucional federal; f) das decisões do plenário ou órgão especial aos quais eles estiverem funcionalmente vinculados².

2 Evidentemente surgirão críticas ao rol definido pelo legislador. A postura deste texto, contudo, partindo da constatação de que os precedentes são antes de tudo vinculantes do ponto de vista racional (ZANETI JR., Hermes. O valor vinculante dos precedentes, passim), é admitir esse rol como um ponto de referência normativo e formal. Apenas para ilustrar, mencionaremos dois recentes textos que diferem neste ponto. O primeiro defende que «Apenas o Supremo Tribunal Federal e o Superior Tribunal de Justiça formam precedentes» e que «Os Tribunais Regionais Federais e os Tribunais de Justiça formam jurisprudência», Cfr. MARINONI, Luiz Guilherme, ARENHART, Sérgio Cruz e MITIDIERO, Daniel. Novo Curso de Processo Civil. Tutela dos Direitos Mediante Procedimento Comum. Volume II. São Paulo: Revista dos Tribunais, 2015; p. 613. Observe-se que admitir que os Tribunais Regionais Federais e os Tribunais de Justiça formam jurisprudência significa eliminar todas as técnicas de controle argumentativo das decisões destes tribunais (arts. $489, \S 1^{\circ}$ e art. 10), quando eles deixarem de aplicar as suas próprias decisões anteriores, e, em especial, importa negar o caráter vinculante das decisões dos próprios Tribunais de Justiça em matéria local (direito local estadual), para os quais os Tribunais de Justiça são a última instância. Por outro lado, o segundo, afirma que a vinculação às súmulas constitui ampliação da competência do tribunal, o que somente poderia ocorrer por emenda constitucional, alegando ainda que: «qual a diferença entre uma Súmula "comum" do STF ou do STJ de um lado e uma Súmula vinculante do outro? Se todas, afinal, vincularão, então por que diferenciar? Será que a única diferença é quanto à possibilidade de Reclamação (art. 985 [rectius: 988])? A questão que fica é: pode-se aumentar a competência de Tribunal a não ser via emenda à Constituição?» THEODORO JR., Humberto; NUNES, Dierle, BAHIA, Alexandre Melo Franco e PEDRON, Flávio Quinaud. Novo CPC. Fundamentos e sistematização. Rio de Janeiro: Forense, 2015; p. 312. Neste caso, nos parece, deve ficar claro que a atribuição de eficácia normativa formalmente vinculante às súmulas não tem nenhuma relação com a competência do tribunal, pois não se está questionando a sua competência. Aliás, todos sabem e é notório que Constituição garante ao STF e ao STJ a função de dar unidade interpretativa, respectivamente, ao direito constitucional e infraconstitucional. As súmulas serviriam para quê? Para nada? Evidentemente, estabelecendo-se uma regra de racionalidade, as súmulas devem vincular (antes de tudo o próprio tribunal). Assim, sendo as súmulas - desde que ligadas aos fundamentos determinantes de fato e de direito dos casos que Ihes deram origem e com eles conjuntamente interpretadas - o extrato dos precedentes, elas funcionarão como uma técnica de divulgação da ratio decidendi, conforme o entendimento do próprio tribunal. Portanto, negar vinculatividade, seria negar qualquer utilidade a esta técnica. Qual a diferença então entre as súmulas e as súmulas vinculantes? Antes de tudo, o quorum de estabelecimento e modificação. No caso das súmulas vinculantes, o quorum será por decisão de dois terços de seus membros (art. 103-A, caput, $C F / 88$, incluído pela $E C n^{\circ} 45 / 2004$ ). Há ainda a possibilidade expressa de reclamação (art. 988, IV, CPC c/c art. 103-A, § 3, CF/88), mas existe outras diferenças, como a diferença topológica no rol do CPC, qual seja, na eventual concorrência entre súmulas (incisos II e IV), prevalente será a súmula vinculante. Além disto, para concluir, as súmulas vinculantes obrigarão também os órgãos da administração pública direta e indireta, nas esferas federal, estadual e municipal, pelo que sua eficácia vinculante expressa vai além daquela prevista no art. 927 do CPC (art. 103-A, caput). Justamente por tais razões, independentemente da vinculatividade das súmulas no novo CPC, o STF recentemente converteu nove súmulas em súmulas vinculantes, conforme se verifica nos enunciados da súmula vinculante n. 38 (645), 39 (647), 40 (666), 41 (670), 42 (681), 43 (685), 44 (686), 45 (721), 46 (722), com indicação dos precedentes e dos debates no site do Tribunal (www.stf.jus.br). Próximo ao 
Há, nestes dispositivos, a clara obrigatoriedade de os juízes e tribunais de aplicarem as próprias decisões e as decisões dos tribunais superiores, principalmente, como normas — não como conselhos ou boas razões, mas levando a sério as decisões judiciais anteriores, já que estas passam a ser obrigatórias para o caso concreto e para os casos futuros, em um duplo discurso jurídico (discurso da decisão do caso concreto e discurso do precedente). ${ }^{3}$ "No Brasil, há precedentes com força vinculante- é dizer, em que a ratio decidendi contida na fundamentação de um julgado tem força vinculante. Estão eles enumerados no art. 927, CPC» .

Com isto, podemos identificar a normatividade dos precedentes (caracterizada pelo dever ser, seu caráter deontológico, portanto, normativo), a sua vinculatividade (demarcada pela sua obrigatoriedade. A lei não contém palavras inúteis e, quando para além dos deveres de estabilidade, coerência e integridade, o dispositivo fala em juízes e tribunais observarão, trata-se de uma vinculação de caráter jurídico) ${ }^{5}$ e o seu caráter de fonte formal (os precedentes são reconhecidos formalmente como fonte pela legislação processual que determina sua aplicação normativa e vinculante no direito material ou processual).

A mudança de paradigma consiste em abandonar o caráter meramente persuasivo da jurisprudência anterior (precedentes persuasivos) para assumir o papel normativo dos precedentes atuais (precedentes vinculantes).

nosso entendimento, cf. DIDIER JR., Fredie, BRAGA, Paula Sarno e OLIVEIRA, Rafael. Curso de direito processual civil. Teoria da prova, direito probatório, teoria do precedente, decisão judicial, coisa julgada e antecipação dos efeitos da tutela. Volume 2. 10. ${ }^{a}$ ed. Salvador: Jus Podivm, 2014, seção 3.3.2.2.

3 MITIDIERO, Daniel. «Fundamentação e precedente: dois discursos a partir da decisão judicial». In: MITIDIERO, Daniel e Guilherme RIZZO (coordenadores). Maria Angélica Echer Ferreira Feijó (organizador). Processo civil. Estudos em homenagem ao Professor Doutor Carlos Alberto Alvaro de Oliveira. São Paulo: Atlas, 2012; pp. 85-99; esp. p. 91; DIDIER JR., Fredie, BRAGA, Paula Sarno e OLIVEIRA, Rafael. Curso de direito processual civil. Teoria da prova, direito probatório, teoria do precedente, decisão judicial, coisa julgada e antecipação dos efeitos da tutela. Volume 2. 10. ${ }^{a}$ ed. Salvador: Jus Podivm, 2014; seção 1.1.

4 DIDIER JR., Fredie, BRAGA, Paula Sarno e OLIVEIRA, Rafael. Ob. cit. Curso de direito processual civil. Teoria da prova, direito probatório, teoria do precedente, decisão judicial, coisa julgada e antecipação dos efeitos da tutela. Volume 2. 10. ${ }^{a}$ ed. Salvador: Jus Podivm, 2014 ; seção 3.2.2.

5 Apenas para ilustrar a força normativa deste termo sugiro a leitura de Kelsen, «o problema da liberdade», no qual fica clara a diferença entre o ser e o dever ser, entre causalidade e imputação (KELSEN, Hans. Teoria pura do Direito. Volume I. 2. ${ }^{a}$ ed. trad. João Baptista Machado. Coimbra: Arménio Amado; pp. 179 ss.). Note-se ademais que o art. 927, $\S 1^{\circ}$ refere ao mesmo termo "observarão» em relação aos arts. 10 e $489, \S 1^{\circ}$ do CPC que são de observância obrigatória por implicarem em nulidade da decisão. Logo, a inobservância do art. 927 e incisos atrai a incidência das referidas normas, completando o suporte fático com a consequência jurídica. 
A finalidade desta mudança está em assegurar racionalidade ao direito e, ao mesmo tempo, reduzir a discricionariedade judicial e o ativismo judicial subjetivista e decisionista. Justamente por isto estas decisões foram expressamente vinculadas a fundamentação adequada, art. 489, $\S 1^{\circ}$, especialmente incisos $V$ (fundamentos determinantes) e VI (distinção e superação), e a vedação das decisões surpresa (art. 10).

A defesa da regra da universalização é feita por grande parte da doutrina, Marina Gáscon, Neil MacCormick, Frederick Schaver, Martin Kriele, Robert Alexy, Michele Taruffo, Thomas Bustamante, Luiz Guilherme Marinoni, Sérgio Cruz Arenhart, Daniel Mitidieró6.

A universalização é mais ampla que a igualdade. Para além de incluir a premissa da igualdade, a universalização exige que os juízes dos casosfuturos tenham, a partir da adoção de um pesado ônus argumentativo decorrente da regra da universalização, o dever (normativo) de seguir os precedentes de forma adequada, afastando a presunção a favor do precedente, quando o caso deva ser julgado de forma diferente (ônus argumentativo e pretensão de correção).

Os princípios da igualdade e segurança jurídica, normalmente elencados para justificar a teoria dos precedentes, são, portanto, consequências colaterais do atendimento da racionalidade e universabilidade das decisões.

6 GASCÓN, Marina. «Rationality and (self) precedent: brief considerations concerning the rounding and implications of the rule of self-precedent». In Thomas Bustamante; Carlos Bernal Pulido (editores). On the Philosophy of Precedent: Proceedings of the 24th World Congress of the International Association for Philosophy of Law and Social Philosophy. Volume III. Stuttgart/Sinzheim: Franz Steiner Verlag/Nomos, 2012; pp. 35- 50; p. 39; MACCORMICK, Neil. «La argumentación y la interpretación en el Derecho». In Revista Vasca de Administración Pública n. ${ }^{\circ}$ 36/201-217, 1993; esp. p. 203; SCHAUER, Frederick. «Precedent». Stanford Law Review, Volume 39. Fevereiro 1987; p. 571 ; p. 595 e 596; KRIELE, Martin. «ll precedente nell'ambito giuridico europeo-continentale e angloamericano». Trad. Giuseppe Zaccaria. In: La sentenza in Europa. Metodo, tecnica e stile. Padova: CEDAM, 1988; pp. 515-528; p. 521 ; ALEXY, Robert. Teoría de la argumentación jurídica [1983]. Trad. Manuel Atienza e Isabel Espejo, 2. ${ }^{a}$ ed. Madrid: Centro de Estudios Políticos y Constitucionales, 2007; pp. 262265; TARUFFO, Michele, Precedente e giurisprudenza. Napoli: Editoriale Scientifica, 2007, pp. 38-40; BUSTAMANTE, Thomas. «Finding analogies between cases». In BUSTAMANTE, Thomas; PULIDO, Carlos Bernal (editores). On the philosophy of precedent: Proceedings of the 24th World Congress of the International Association for Philosophy of Law and Social Philosophy, Volume III. Stuttgart/Sinzheim: Franz Steiner Verlag/Nomos, 2012; pp. 59-71; p. 68; MARINONI, Luiz Guilherme, ARENHART, Sérgio Cruz e MITIDIERO, Daniel. Novo curso de processo civil. Tutela dos direitos mediante procedimento comum. Volume II, São Paulo: Editora Revista dos Tribunais, 2015; p. 613. Próximos, falando em parametricidade, a partir das lições de Robert Summers e Neil MacCormick, THEODORO JR., Humberto, NUNES, Dierle, BAHIA, Alexandre Melo Franco e PEDRON, Flávio Quinaud. Novo CPC. Fundamentos e sistematização. Rio de Janeiro: Forense, 2015; p. 292. 
O direito processual civil brasileiro acertou, ao reconhecer formalmente, no texto legal, a força normativa dos precedentes. Com isto, tornou-os obrigatórios e vinculantes, induzindo a passagem do direito jurisprudencial — vinculado apenas à lei e ao livre convencimento do juiz, na sua falta-, para o direito de precedentes, no qual os juízes e tribunais são responsáveis por suas escolhas, escolhas que irão vincular a si e aos seus pares no futuro; portanto, não são mais «livres», se é que um dia o foram.

A melhor doutrina já exigia a compreensão dos precedentes dos tribunais como obrigatórios, independentemente de mudança na legislação ${ }^{7}$. A nova legislação processual, contudo, representa uma forte ferramenta para uma mudança de todas as regras e princípios que regiam a formação e a aplicação dos precedentes no direito anterior. Esse é o sentido de mudança que deve ser reconhecido no novo CPC/2015. Afinal, se as regras e os princípios de um ordenamento jurídico podem mudar, nada mais correto que reconhecer que a lei nova é uma das formas de realizar esta mudança ${ }^{8}$.

\subsection{Padronização judicial e a função do jurista: comunidade de trabalho}

Direito é construído e determinado por ele mesmo, são os textos escritos pelos homens que thes dão o conteúdo, os limites e a conformação. Por essa razão, por ser produto da ação e da inteligência humana, o direito é artificial, e, nos Estados Democráticos Constitucionais, está a serviço dos direitos fundamentais do cidadão, não dos interesses do Estado e da burocracia judicial. Por isto, o modelo de precedentes, corretamente aplicado, jamais poderá significar uma simplória padronização das decisões judiciais. $\bigcirc$ juiz e os juristas não são máquinas, mas seres pensantes, inteligentes e capazes de interpretar os precedentes assim como interpretam os textos da lei. A norma é sempre o resultado da interpretação. Todos os textos, sejam eles textos legais, sejam precedentes judiciais, exigem interpretação. A tarefa de interpretar é típica dos juízes e juristas.

Hoje, com o modelo de precedentes, teremos de repensar a metodologia de trabalho dos juízes, advogados, professores e de todos aqueles que escrevem e pensam o Direito - a comunidade de trabalho dos juristas. $\bigcirc$ exemplo dos processualistas civis é digno de ser referido, uma vez que, obje-

7 MARINONI, Luiz Guilherme. Precedentes obrigatórios. São Paulo: Editora Revista dos Tribunais, 2010. MITIDIERO, Daniel. Cortes superiores e cortes supremas. Do controle à interpretação, da jurisprudência ao precedente. São Paulo: Editora Revista dos Tribunais, 2014.

8 MACCORMICK, Neil. Legal reasoning and legal theory. New York: Oxford University Press, 1978, reprinted 2003; p. 154. 
tivamente, serão os mais afetados imediatamente, já que a mudança principia pelo CPC. Ademais, os processualistas foram formados para interpretar o processo insulados no seu campo de pesquisa e estudavam os institutos do Código de Processo Civil em separado, limitando-se à análise dos dispositivos legais em uma interpretação legalista formalista. $\bigcirc$ Código novo exigirá uma radical mudança na forma de interpretar o direito. A interpretação não poderá mais ser feita aos pedaços. A leitura do CPC deverá ser efetuada a partir de uma unidade de propósitos, de uma leitura harmônica do todo, pensada, claramente, a partir de sua conformação constitucional, à luz do Estado Democrático Constitucional e da tutela dos direitos fundamentais, de acordo com a nova interpretação jurídica e a nova hermenêutica constitucional (arts. $1^{\circ}, 8^{\circ}, 489, \S 1^{\circ}$ e 926 do CPC/2015, entre outros).

Portanto, este momento requer a aplicação de uma interpretação realista moderada e responsável, ou seja, uma interpretação comprometida com o texto e com o contexto, apresentando uma fidelidade dinâmica ao texto e ao ordenamento jurídico visto em sua unidade e coerência. Esta interpretação, ao mesmo tempo em que reconhece a necessidade de interpretação de todo e qualquer texto, uma vez que texto e norma não se confundem, corrigindo o desvio formalista interpretativo, busca eliminar os erros de afirmações absurdas, subjetivistas e arbitrárias, eliminando o vício realista do decisionismo judicial?.

\subsection{Compreensão do Código a partir da Constituição: prece- dentes como modelo pensado a partir dos deveres consti- tucionais de coerência e integridade}

Como vimos, o Código deve ser compreendido em seu conjunto e em harmonia com a Constituição (art. 1ㄷ, CPC/2015), evitando-se interpretações bizarras, fruto de ignorância ou inaceitável arbítrio. $\bigcirc$ processualista deverá compreender, cada vez mais, o modelo constitucional do processo. É importante essa ressalva porque, isoladamente interpretados, alguns institutos do CPC/2015 não revelam esta mudança de direção; por outro lado, tais institutos, se interpretados em conjunto, demonstram mudança inegável. Neste sentido, a eliminação do «livre» convencimento judicial (art. 371), a fundamentação adequada $\left(489, \S 1^{\circ}\right)$, a justificação interna

9 CAPPELLETTI, Mauro. The judicial process in comparative perspective. Oxford: Oxford University Press/Clarendon Press, 1991; p. 208. CHIASSONI, Pierluigi. Tecnica dell'interpretazione giuridica. Bologna: II Mulino, 2007. ZANETI JR., Hermes. O valor vinculante dos precedentes; p. 145; PINO, Giorgio. Diritti e Interpretazione. Il Ragionamento Giuridico nello Stato Costituzionale. Bologna: II Mulino, 2010; p. 15. 
e externa, fática e jurídica, com exigências para utilização da ponderação como método de solução da colisão entre normas (art. 489, $\S 2^{\circ}$ ) e os deveres de estabilidade, coerência e integridade (art. 926), são exemplos de exigências interpretativas do novo diploma que vão muito além do modelo legalista e da interpretação-formalista ${ }^{10}$.

Com o CPC/2015, suplantou-se, em definitivo, o paradoxo metodológico da justiça brasileira, que tinha sua matriz constitucional na Constituição Republicana de 1891, com nítida influência do common law norte-americano e tinha sua matriz infraconstitucional no direito do civil law, a exemplo do CPC/1973 ${ }^{11}$. Hoje, com o novo CPC, temos uma só lei processual (figurativamente é claro), com elementos de common law e civil law, abaixo de uma só Constituição, ambas, portanto, com natureza híbrida. Equal justice under Law, igual justiça sob o Direito.

Definitivamente avançamos em relação aos modelos privatistas e publicistas de processo, ligados ao CPC/1973, dando um salto diretamente para o paradigma constitucional que combina, ao mesmo tempo, direitos liberais e direitos sociais, direito individuais e coletivos, direito público e direito privado, na matriz pluralista do Estado Democrático Constitucional.

A teoria dos precedentes normativos vinculantes é um claro exemplo desta mudança paradigmática, pois os juízes e tribunais são menos livres e mais responsáveis pela interpretação no quadro da teoria dos precedentes do que no quadro da mera legalidade. Lei e precedentes vinculam, ambos têm caráter normativo. A mudança mais clara é esta. $O$ modelo de precedentes não é uma forma de liberar o juiz da lei, mas um método de vincular a discricionariedade do juiz na interpretação da lei, controlando a sua autoridade de forma democrática, tendo como parâmetro a universa-

10 O CPC não adota uma teoria da justiça, acena, contudo, para dois caminhos, a teoria de Robert Alexy e a teoria de Ronald Dworkin. Basta a leitura dos arts. $8^{\circ}$ e $489, \S 2^{\circ}$ para perceber a influência de Robert Alexy. A leitura do art. 926 claramente adota a concepção teórica de Dworkin. O caminho pragmático de utilizar os pontos convergentes entre as duas conhecidas compreensões teóricas nos parece mais adequado. Não se pode questionar - papel de fechamento da discricionariedade do juiz que ambas teorias pretendem alcançar. Os modelos de princípios adotados por ambos autores servem como limites à liberdade de interpretação deixada como espaço irredutível no positivismo hartiano. Cf., por todos, demostrando como há grave distorção no debate brasileiro: MICHELON, Claudio. «Princípios e coerência na argumentação jurídica». In Ronaldo Porto Macedo Jr; Catarina Helena Cortada Barbieri (coordenadores). Direito e interpretação: racionalidade e instituições. São Paulo: Saraiva, 2011 ; pp. 261 e 262.

11 ZANETI JR., Hermes. A Constitucionalização do Processo. O modelo constitucional da justiça brasileira e as relações entre processo e constituição. São Paulo: Atlas, 2014, tese original desenvolvida em 2005, como requisito para conclusão do curso de doutorado junto à Universidade Federal do Rio Grande do Sul. 
lização da decisão para os casos futuros (formação do precedente) e o já decidido nos casos anteriores (aplicação do precedente).

\section{DIREITO JURISPRUDENCIAL OU PRECEDENTES?}

Para superar o paradigma do Código anterior, compreendendo adequadamente a mudança ocorrida com os arts. 926 e 927 do CPC/2015, devemos deixar de utilizar, no vocabulário teórico brasileiro, a expressão «direito jurisprudencial». Há uma forte razão para isto. A expressão carrega dois problemas de ordem teórica que a tornam incompatível com a teoria dos precedentes normativos formalmente vinculantes ora vigente: o primeiro é ligado ao jusnaturalismo; o segundo, ligado ao juspositivismo.

Os dois tópicos a seguir tratarão destes dois problemas.

\subsection{Dever de coerência/consistência, dever de integridade/ coerência em sentido amplo e o abandono do "livre» con- vencimento do juiz (paleojusnaturalismo)}

Quanto ao primeiro problema, pode-se dizer que a doutrina da jurisprudência, ou do direito jurisprudencial, é vinculada a postulados pré-modernos, paleojusnaturalistas, isto é, o jusnaturalismo mais antigo, anterior à recepção do Direito Natural normatizada em princípios constitucionais.

A jurisprudência, compreendida como conjunto reiterado de decisões no Brasil, revela-se técnica ultrapassada, em prejuízo da racionalidade da decisão e em benefício da decisão individualizada para o caso concreto, ensejando toda sorte de subjetivismos e contradições. O mesmo tribunal, muitas vezes, o mesmo órgão fracionário (sessão, câmara, turma etc.), decide em contraste com as suas decisões anteriores ao mesmo tempo (contrastes sincrônicos) ou em tempos distintos (contrastes diacrônicos) $)^{12}$.

12 A doutrina a respeito fala dos contrastes sincrônicos (ao mesmo tempo) e diacrônicos (em momentos diferentes) apontando para a inexistência de um coerente sistema de precedentes. Na Itália o problema dos contrastes da Corte de Cassação foi extensamente mapeado. A necessidade de uma harmonização jurisprudencial é reconhecida e estimulada, mas infelizmente nem sempre é obtida, Cfr. CHIARLONI, Sergio. «ll diritto vivente di fronte alla valanga dei ricorsi in Cassazione: I'inammissibilità per violazione del c.d. principio di autosufficienza». In: http://www.processocivile.org/chiarloni\%5Cart0002.html, acesso em 18.01.2014, seção 2; CHIARLONI, Sergio. «Sui rapporti tra funzione nomofilattica della cassazione e principio della ragionevole durata del processo». Giustizia insieme, Roma: Aracne, 2009; pp. 21 -33, seção 2; CHIARLONI, Sergio. "Efficacia del precedente giudiziario e tipologia dei contrasti di giurisprudenza». Revista de Processo, São Paulo: Revista dos Tribunais, Volume 229. ano 39. Março 2014; p. 403. Sobre os contrastes na jurisprudência da Corte de Cassação e sua insuficiência, no modelo atual, para garantir 
Isso ocorre porque, a jurisprudência, via de regra, particulariza o caso de tal forma e sorte, escolhendo raciocinar pela exceção, para que a solução aplique-se tão só e apenas àquele caso e aos casos em que o julgador entender correta a decisão reiterada dos tribunais, tomando a decisão anterior como exemplo de boa decisão (precedentes persuasivos, ad exemplum ou de facto). Essa técnica de decidir é baseada na opinião do tribunal, e não na sua vinculação aos próprios precedentes. Em outras palavras, pode-se dizer que a jurisprudência só será aplicável, quando o tribunal disser que ela resolve bem o caso, bastando, por outro lado, o tribunal entender que as razões que fundamentaram o julgamento anterior não eram «boas», para não utilizá-las novamente para o julgamento do novo caso. A rigor ele nem precisa justificar a sua não utilização, pois as decisões anteriores são absolutamente desprovidas de caráter normativo.

¡julgador, que é livre para optar pelas «boas razões» (razões subjetivas), não está vinculado aos precedentes e não tem o dever de testar a universabilidade dos fundamentos determinantes fáticos e jurídicos de suas decisões ${ }^{13}$.

a função nomofilácica na Itália cf. TARUFFO, Michele. Precedente e giurisprudenza, Op. Cit.; pp. 19 e 20; MONETA, Gabriele. I mutamenti nella giurisprudenza della Cassazione Civile. Ottocentosessantasette casi di contrasto nel quinquennio 1988-1992. Padova: CEDAM, 1993; MONETA, Gabriele. Conflitti giurisprudenziali in Cassazione. I contrasti della Cassazione Civile dal settembre 1993 al dicembre 1994. Padova: CEDAM, 1995.

13 Há grande convergência na teoria jurídica e na filosofia jurídica atual sobre a importância dos deveres de consistência/coerência em sentido estrito e integridade/coerência em sentido amplo. A coerência, no sentido amplo (integridade), é um tema central para a teoria do direito hoje. Por isso, é melhor compreender integridade, do CPC/2015, como coerência em sentido amplo, desfazendo a conexão forte com a concepção de integridade em Dworkin (AARNIO, Aulis. Essays on the Doctrinal Study of Law. London/New York: Springer, 2011; pp. 144-146). Adotaremos, neste texto, como já se pode perceber a menção aos pares conceituais. Não se trata de mera questão de nomes, mas desfazer a atração para o CPC/2015 de uma vertente da filosofia jurídica muito forte, que pretende, com a noção de integridade, a admissão da teoria da única resposta correta (Dworkin). Esta respeitável opção teórica é incompatível, por exemplo, com a ponderação e a proporcionalidade igualmente previstas no CPC (art. 489, $\S 2^{\circ}$ e art. $8^{\circ}$ ). A interpretação do novo CPC deve preservar a unidade do texto, a unidade da Constituição e a tradição jurídica, dando um sentido às palavras que garanta a consistência interna à nova lei. Portanto, para corretamente compreender os deveres de coerência/consistência (em sentido estrito, dever de não-contradição) e integridade/coerência (coerência normativa em sentido amplo), eles devem ser considerados como pares conceituais. Esta é a melhor solução para o problema da integridade/coerência no novo CPC. Justamente por isso, defendemos a convergência — sem identidade absoluta - entre as teorias de Dworkin e MacCormick, entre os termos integridade e coerência em sentido amplo, convergência já admitida pela doutrina brasileira (MARTINS, Argemiro, ROESLER, Cláudia e JESUS, Ricardo. A noção de coerência na teoria da argumentação jurídica de Neil MacCormick. Novos Estudos Jurídicos, Volume 16, n. ${ }^{2}$ 2. março-agosto 2011 ; pp. 207-221. In: www6.univali.br, acesso em: 01.12.2014; STRECK, Lenio Luiz. Novo CPC terá mecanismos para combater decisionismos e arbitrariedades?, Op. cit., acesso em 23.12.2014, nota 07) e internacional (AARNIO, Aulis. Essays on the Doctrinal Study of Law. Ob. cit.; p. 145; 
Nega-se, assim, o dever de coerência/consistência em sentido estrito, compreendida como não-contradição com as decisões anteriores do mesmo julgador, do mesmo tribunal e do mesmo ordenamento jurídico, e o dever de integridade/coerência em sentido amplo, compreendida como a conformidade da decisão com a unidade do ordenamento jurídico como um todo (art. 926, caput), e, ao mesmo tempo, o caráter normativo da norma-precedente (art. 927, $\S 1^{\circ}$ e $\left.489, \S 1^{\circ}, \mathrm{VI}\right)^{14}$.

Indiscutível, ainda, a abertura recursal que este comportamento provoca, pela ausência de estabilidade das decisões proferidas pelo tribunal (art. 926, caput).

Portanto, o «direito jurisprudencial» entendido na concepção paleojusnaturalista, ao invés de visualizar categorias mais amplas e universalizáveis, restringe-se, em todos os casos em que não se quer seguir a jurisprudência, ao detalhe, à diferenças sutis, ao particularismo (e ao subjetivismo, que dele decorre), sem procurar uma razão de decidir que seja aplicável para caso presente e para todos os casos futuros similares ou análogos.

PECZENICK, Aleksander. Certainty or coherence? In: KRAWIETZ, Werner et al. (editores). The Reasonable as Rational? On Legal Argumentation and Justifiction. Festschrift for Aulis Aarnio. Berlin: Duncker un Humblot, 2000; p. 169). A convergência coerência/integridade limita-se a reconhecer o aspecto mais amplo dos conceitos de coerência e integridade, ligados aos princípios e a possibilidade de dar um sentido de conjunto às normas jurídicas («hanging together» e «making sense»), a partir da justificação das decisões judiciais em um contexto mais geral de unidade do direito (MACCORMICK, Neil. Coherence in legal justification. In: PECZENIK, Aleksander; LINDAHL, L. e van ROERMUND, G.C. (editores). Theory of Legal Science. Dordrecht: Springer, 1984; pp. 235-251). Este é o principal dever previsto no art. 926,

14 O CPC/2015, ao referir aos termos «coerência e integridade», utilizou a terminologia de Ronald Dworkin (DWORKIN, Ronald. O império do direito. Trad. Jéferson L. Camargo. São Paulo: Martins Fontes, 2003; pp. 63-69; STRECK, Lenio Luiz. Novo CPC terá mecanismos para combater decisionismos e arbitrariedades? Senso incomum, Conjur. In: www.conjur.com.br, acesso em 23.12.2014; THEODORO JR., Humberto, NUNES, Dierle e BAHIA, Alexandre Melo Franco; PEDRON, Flávio Quinaud. Novo CPC. Fundamentos e Sistematização; p. 306). Isto contudo não significa que o CPC siga a doutrina de Dworkin. Observe-se, ainda, na doutrina crítica, o entendimento de que os precedentes não devem seguir a teoria do direito de Dworkin em DIDIER JR., Fredie, BRAGA, Paula Sarno e OLIVEIRA, Rafael. Curso de direito processual civil. Teoria da prova, direito probatório, teoria do precedente, decisão judicial, coisa julgada e antecipação dos efeitos da tutela. Volume 2. 10. ${ }^{a}$ ed. Salvador: Jus Podivm, 2014 ; seção 4.5.1 e MARINONI, Luiz Guilherme, ARENHART, Sérgio Cruz e MITIDIERO, Daniel. Novo Curso de Processo Civil. Tutela dos Direitos Mediante Procedimento Comum. São Paulo: Revista dos Tribunais Volume II. 2015; p. 611. Outra vertente teórica que chega às mesmas conclusões, ou pelo menos a conclusões muito próximas as de Dworkin, decorre dos trabalhos de Neil MacCormick (MACCORMICK, Neil. Rhetoric and the Rule of Law. A Theory of Legal Reasoning. New York: Oxford University Press, 2005; p. 190; Id. Coherence in legal justification. In.: PECZENIK, Aleksander; LINDAHL, L.; van ROERMUND, G.C. (editores). Theory of Legal Science. Dordrecht: Springer, 1984; pp. 235-251; ld. Legal Reasoning and Legal Theory. New York: Oxford University Press, 1978; Cap. VII e VIII, reprinted, 2003). MacCormick adota os termos «consistência» e «coerência» (coerência normativa). 
A decisão, assim, não é necessariamente universalizável e passa a atender a cada um dos casos isoladamente. Basta perceber que a «doutrina da jurisprudência» afirma a liberdade de interpretar do juiz, escolhendo a «melhor» razão para fundamentar a decisão «justa».

Portanto, a «doutrina da jurisprudência» e a «doutrina do livre convencimento», expurgada do CPC/2015 (art. 371), guardam uma íntima relação. Essa concepção do direito como fonte natural de justiça foi superada, na tradição de civil law, pela "doutrina da legalidade», mas não no Brasil. A forte conexão entre o juiz brasileiro e a «doutrina da jurisprudência» tem origens históricas, culturais e religiosas $^{15}$. $O$ retorno do paleojusnaturalismo não contribui para resolver os graves problemas da aplicação no direito no Brasil.

Marcada pelo personalismo e pela predominância do senso de justiça individual, a «doutrina da jurisprudência» acaba por permitir, inconstitucionalmente, que os tribunais, e não o legislador, determinem as boas razões para a tomada das decisões, caso a caso, determinando um modelo de justiça casuísta.

Não é este o caso da teoria dos precedentes, que procura limitar a discricionariedade dos julgadores, vinculando-os às próprias decisões, constrangendo o julgador a racionalizar sua decisão e elaborar categorias de fato suficientemente amplas para que, nos casos futuros, a decisão tenha impacto em todos os casos similares ou análogos. Dessa forma, podemos concluir que o primeiro problema teórico que nos impede de melhor compreender a teoria dos precedentes é o ranço existente na tradição do "direito jurisprudencial», que, ao deixar o juiz livre para decidir como ele quiser, de acordo com suas concepções subjetivas de justiça (paleojusnaturalismo), nega a vinculatividade do juiz e do próprio tribunal aos seus precedentes.

\subsection{Dever de coerência/consistência, dever de integridade/ coerência em sentido amplo e o abandono da centralida- de exclusiva da lei como fonte primária e formal do direi- to (paleojuspositivismo)}

Quanto ao segundo problema, é importante referir que a jurisprudência, na concepção paleojuspositivista da tradição de civil law — doutrina da mera legalidade - não tem força normativa de fonte primária. Por isso, a força normativa formalmente vinculante dos precedentes, na atual redação

15 MARINONI, Luiz Guilherme. A ética dos precedentes. São Paulo: Editora Revista dos Tribunais, 2014. 
dos arts. 926 e 927 do CPC/2015, combinados com os incisos $\mathrm{V}$ e $\mathrm{VI}$ do art. 489, é incompatível com o paleojuspositivismo e, consequentemente, com o modelo tradicional de common law.

Percebe-se, na «doutrina da jurisprudência», uma fraqueza diante dos argumentos de direito estrito, pois, pela tradição atual do civil law, após a adoção do princípio da legalidade (centralidade da lei como fonte formal primária do direito), não há falar-se de «direito jurisprudencial» no sentido de fonte primária — não constituem as decisões dos tribunais uma fonte normativa formalmente vinculante, sendo seu valor o mesmo valor atribuído para a doutrina e para os costumes - meras fontes secundárias. Escamoteadas por fontes sem importância, as fontes secundárias decidem apenas os casos em que o próprio tribunal decide aplicá-las, sem que sejam submetidas ao rigoroso controle da crítica, certamente uma operação lógica não muito transparente.

Por esta razão, entre os teóricos da tradição de civil law é muito comum encontrar a justificativa para a força normativa secundária da jurisprudência no mesmo grupo de fontes destinadas ao direito consuetudinário, à analogia e ao direito doutrinário (art. $4^{\circ}, \mathrm{LINDB}$ ), servindo como fonte apenas na omissão normativa, na falta das leis ${ }^{16}$. Portanto, os dois problemas referidos acima demonstram que uma interpretação do novo Código que consagre o conceito de «direito jurisprudencial» deixa de perceber a mudança de paradigma ocorrida na lei processual, mantendo a tradição brasileira que oscila entre o personalismo paleojusnaturalista subjetivista e o (falso) caráter secundário do Poder Judiciário no paleojuspositivismo legalista, que também resulta em personalismo, casuísmo e subjetivismo degenerável em decisionismo. Fosse para manter esta tradição, não haveria de se escrever uma nova lei, esta já era a tradição brasileira da jurispru-

16 LARENZ, Karl. Metodologia da ciência do direito. Trad. José Lamego. 3. ${ }^{a}$ ed. Lisboa: Fundação Calouste Gulbenkian, 1997; pp. 610 e ss. A noção é profundamente arraigada na dogmática alemã, capitaneada por Savigny, como demonstra Giuseppe Zaccaria: "Quest'estensione della categoria di consuetudine giudiziaria consente in sostanza di riconoscere alla giurisprudenza la dignità di fonte del diritto. Era stato Savigny per primo a considerare i precedenti come diritto consuetudinario e come momento del diritto scientifico: e all'interno della cultura giuridica tedesca giocano un ruolo assai importante, tra Otto e Novecento, l'influsso della Scuola storica del diritto e l'idea che il diritto entra a far parte e si afferma nella vita della comunità essenzialmente attraverso la pratica dei giuristi [...] uso giudiziale e del diritto consuetudinario giudiziale [...] usus fori [...] la via del diritto consuetudinario altro no sai che un mascheramento ideologico — basato non a caso su un'idea ampiamente diffusa, fin dalla Scuola storica del diritto, nella cultura giuridica tedesca- com la funzione di occultare una conclusione che in quel momento storico non si può ancora esplicitamente riconoscere, e cioè la natura di fonte di diritto tout court del Richterrecht». ZACCARIA, Giuseppe. La giurisprudenza come fonte di diritto. Un'evoluzione storica e teorica. Napoli: Editoriale Scientifica, 2007; pp. 9-11. 
dência persuasiva, atávica em nossa cultura, herdada de Portugal. É, em razão da «doutrina do direito jurisprudencial», que temos hoje o «caos de jurisprudências» instalado no Brasil fruto das diversas contradições internas dos tribunais superiores e da inobservância de suas decisões pelos juízes e tribunais inferiores ${ }^{17}$.

\section{A NORMATIVIDADE DOS PRECEDENTES NO ART. 927 DO CPC}

O brasileiro, nos últimos anos, passou a usar cinto de segurança, parou de fumar em lugares públicos fechados e começa a respeitar o gênero e as opções de vida das pessoas, graças às mudanças legislativas ocorridas depois da Constituição de 1988. A lei, portanto, é um poderoso indutor das mudanças culturais ${ }^{18}$.

O art. 927 apresenta o rol de precedentes que, segundo a legislação processual, serão considerados vinculantes. A força normativa dos precedentes será diferenciada, conforme caibam ou não o estabelecimento de quórum qualificado para formação, ampliação, revogação ou superação do precedente e seu desrespeito enseje ou não a impugnação por meio de reclamação (art. 988, II, III e IV, CPC/2015).

Analisemos brevemente a formação do atual art. 927 do CPC.

Os projetos de Código oscilaram no tratamento dado aos precedentes. No Substitutivo da Câmara dos Deputados (SCD), aprovado em 26.03.2014, a opção pelo modelo de precedentes havia sido bem mais clara do que na versão final prevista nos arts. 926 e 927 da Lei 13.105/2015. Também era

17 Não se trata apenas de importar o modelo de precedentes vinculantes, é preciso também importar a cultura dos precedentes. Conforme apontou a doutrina o Brasil já havia importado os precedentes vinculantes sem importar a cultura. Neste sentido, foi demonstrado empiricamente que falta reponsividade e motivação adequada nas decisões de suspensão e nas decisões que julgam os recursos repetitivos, Cfr. BUSTAMANTE, Thomas da Rosa de. A dificuldade de se criar uma cultura argumentativa do precedente judicial e o desafio do novo CPC, nesta coletânea, citando a pesquisa da UFMG para o CNJ, BUSTAMANTE, Thomas, et all. A força normativa do direito judicial: Uma análise da aplicação prática do precedente no direito brasileiro e dos seus desafios para a legitimação da autoridade do poder judiciário. pesquisa realizada pelo Grupo de Pesquisa constituído na Universidade Federal de Minas Gerais, contratada pelo Conselho Nacional de Justiça (Relatório de Pesquisa). Brasília: Conselho Nacional de Justiça, 2014, pp. 186-187. O art. 927, $\S 1^{\circ}$ e o art. 489, $\S 1^{\circ}$ do CPC podem colaborar para criar esta cultura.

18 No mesmo sentido, mencionando a Lei da Boa Razão, afirma Bustamente que «A nossa história ensina que é possível, sim, mudar um paradigma jurídico a partir de uma decisão política racional», Cfr. BUSTAMANTE, Thomas da Rosa de. A dificuldade de se criar uma cultura argumentativa do precedente judicial e o desafio do novo CPC, nesta coletânea. 
melhor a localização do texto. No SCD, os precedentes apareciam como o Capítulo XV, do Livro I -Do Processo de Conhecimento e do Cumprimento de Sentença, logo após o Capítulo XIV, que tratava da sentença e da coisa julgada.

Os precedentes na redação aprovada na Câmara estavam, portanto, dentro da lógica da teoria da decisão judicial, e não da mera uniformização de jurisprudência. Lá era o local mais adequado para a sua colocação topográfica no $\mathrm{CPC}$, já que os precedentes não dizem respeito aos processos nos tribunais, mas a todas as decisões judiciais. A doutrina já percebeu que «em rigor, a matéria aqui tratada refere-se a qualquer decisão jurisdicional, não apenas ao que ocorre no âmbito dos tribunais» ${ }^{19}$.

Os precedentes serão aplicados, não somente nos tribunais, mas por todos os juízes de primeiro grau. Tratam, portanto, da teoria da decisão judicial e, por essa razão, é incorreta a colocação topográfica dada pela redação final. Perceba-se que o erro vem do projeto originalmente apreciado pelo Senado, o qual tratava, no art. 882, do dever de uniformização e estabilidade, falando em «jurisprudência», não em «precedentes». Percebe-se, contrario sensu, o acerto da tese aqui defendida. Devemos ressaltar ainda que, de arrasto, diversos e importantes parágrafos do modelo de precedentes brasileiro que haviam sido construídos pelo legislador na Câmara dos Deputados foram deletados da versão final aprovada pelo Senado.

Não obstante, a questão há de ser superada pela boa dogmática, capaz de extrair os novos conceitos e sonoridades das partituras entregues, mesmo que nem todas as notas estejam explícitas.

O texto legal somente será aplicável em interpretação conforme à constituição, se reconhecer o intérprete que os precedentes vinculam, que os precedentes obrigam, que os juízes e tribunais observarão os precedentes, para usar a expressão do art. 927, caput, em todas as hipóteses dos incisos ali previstos.

Precedentes, portanto, dizem respeito à teoria da decisão judicial, e não à ultrapassada preocupação da doutrina processual civil com a mera uniformização da jurisprudência.

19 BUENO, Cássio Scarpinella. Projetos de Novo Código de Processo Civil Comparados e Anotados. São Paulo: Saraiva, 2014; p. 442; Tb., ZANETI JR., Hermes. «Precedentes (treat like cases alike) e o novo Código de Processo Civil-Universalização e vinculação horizontal como critérios de racionalidade e a negação da "jurisprudência persuasiva" como base para uma teoria e dogmática dos precedentes no Brasil». Revista de Processo, Volume 235. Setembro 2014. São Paulo: RT; p. 293; esp. pp. 340 e 341. 


\subsection{Jurisprudência persuasiva (vinculação de facto ou ad exem- plum-precedentes persuasivos) e precedentes normativos formalmente vinculantes (vinculação jurídica obrigatória)}

Jurisprudência persuasiva é o conjunto de decisões reiteradas do tribunal que, sem força normativa formalmente vinculante, orientam o julgador subsequente em critérios possíveis de decisão, segundo seu convencimento subjetivo a respeito das razões adotadas. Geralmente a jurisprudência persuasiva será de outro tribunal, até mesmo de outros países. A doutrina chama estas decisões exemplificativas de precedentes persuasivos. A eficácia dos precedentes, na tradição de civil law, seria apenas persuasiva, e não vinculante. Por isto a doutrina brasileira que afirma ser o Brasil um país de civil law não consegue compreender a força vinculante dos precedentes (em verdade, o Brasil não é um país de civil law, mas um país de tradição híbrida-civil law e common law ${ }^{20}$.

Na interpretação correta do novo CPC, precedentes normativos formalmente vinculantes são as decisões passadas (casos-precedentes) que tem eficácia normativa formalmente vinculante para os juízes e tribunais subsequentes (casos-futuros) e são de aplicação obrigatória, independentemente das boas razões da decisão. Não valem como mero exemplo, obrigam.

Assim, precedentes normativos formalmente vinculantes para os juízes e tribunais da Bahia, do Espírito Santo e do Rio Grande do Sul, por exemplo, serão as decisões do pleno STF, em matéria constitucional, e da Corte Especial do STJ, em matéria infraconstitucional. As decisões do Tribunal de Justiça do Rio Grande do Sul não serão precedentes vinculantes para os juízes e tribunais da Bahia e do Espírito Santo, sendo, válidas, apenas como argumentos, exemplos, ou seja, como jurisprudência persuasiva.

Por isto, insistimos na distinção, a jurisprudência e o direito jurisprudencial são baseados unicamente em bons exemplos de decisão, que podem ou não ser seguidos, a depender do juízo crítico do julgador. Daí resultarem na chamada vinculação de facto ou ad exemplum, sem caráter normativo ou força vinculante 21 .

20 VARANO, Vincenzo e BARSOTTI, Vittoria. La tradizione giuridica occidentale, $4 .^{a}$ ed. Torino: Giappichelli, 2010; p. 509; ZANETI JR., Hermes. A constitucionalização do processo. [2005] São Paulo: Atlas, 2014; DIDIER JR, Fredie. Curso de direito processual civil. Introdução ao direito processual civil e processo de conhecimento. Volume 1. 13. ${ }^{a}$ ed. Salvador: Jus Podivm, 2011 ; pp. 41-43.

21 PECZENIK, Aleksander. «Sui precedenti vincolanti de facto». 1996-6. Ragion Pratica; p. 3543; p. 35; PECZENICK, Aleksander, The Binding Force of Precedente. In MACCORMICK, Neil; SUMMERS, Robert (editores). Interpreting precedents. A comparative study. Aldershot: Dartmouth, 1997; pp. 461-479; esp. pp. 466 e 467. 
Ora, a diferença não é pouca, nem sutil. Precedentes vinculam. Jurisprudência persuasiva não vincula.

Assim, um precedente persuasivo vinculante de facto ou ad exemplum, é uma contradição em termos, pois, ao não ter conteúdo normativo, dever ser, imposição e obrigatoriedade, não pode ser vinculante, será apenas persuasivo e seu descumprimento não acarretará violação das fontes primárias formais do ordenamento jurídico.

O CPC/2015 rompeu definitivamente com a tradição brasileira do direito jurisprudencial e da jurisprudência persuasiva, elencando no art. 927 e incisos os casos em que os precedentes no Brasil obrigam, portanto, são normativos e vinculantes, e não meros exemplos de boas decisões. Daí falarmos, nestes casos, de precedentes normativos formalmente vinculantes, uma vez que são normas primárias, estabelecidas como tal pela legislação processual formal, que determina a sua vinculação independentemente de suas boas razões.

\subsection{Os precedentes no Estado Democrático Constitucio- nal: divisão de trabalho entre juízes e legisladores na atividade de interpretação operativa}

Em um Estado Democrático Constitucional, fundante de uma democracia contramajoritária de direitos fundamentais, que, ao mesmo tempo, garante a liberdade política, através da atividade legislativa (princípio democrático) e limita-a, através dos direitos e deveres fundamentais, inevitável será, aos juízes e tribunais, a resolução de questões controversas, polêmicas, difíceis e, nesta atividade, exercer a função de (re)construir o ordenamento jurídico22.

22 Nas palavras de Humberto Ávila: «Além de levar às mencionadas conclusões, o exposto também exige a substituição de algumas crenças tradicionais por conhecimentos mais sólidos: é preciso substituir a conviçção de que o dispositivo identifica-se com a norma, pela constatação de que o dispositivo é o ponto de partida da interpretação; é necessário ultrapassar a crendice de que a função do intérprete é meramente descrever significados, em favor da compreensão de que o intérprete reconstrói sentidos, quer o cientista, pela construção de conexões sintáticas e semânticas, quer o aplicador, que soma àquelas conexões as circunstâncias do caso a julgar; importa deixar de lado a opinião de que o Poder Judiciário só exerce a função de legislador negativo, para compreender que ele concretiza o ordenamento jurídico diante do caso concreto». ÁVILA, Humberto, Teoria dos princípios: da definição à aplicação dos princípios jurídicos. 14. ${ }^{a}$ ed. atualizada. São Paulo: Malheiros, 2013; p. 37, sem grifos no original. Mais recentemente, reforçando o papel da doutrina cf. ÁVILA, Humberto. Ciência do Direito Tributário e Discussão Crítica. Revista Direito Tributário Atual, Volume 32, São Paulo: Dialética, 2014; p. 159. 
A atividade reconstrutiva do ordenamento jurídico pelos juízes e tribunais irá ocorrer mediante a interpretação operativa, entendida esta como aquela interpretação que acrescenta conteúdo reconstruído ao ordenamento ${ }^{23}$, conferindo-lhe, nas palauras do novo Código, coerência e integridade (art. 926). A exemplo deste tipo de interpretação operativa, podemos citar a que ocorre na densificação de normas-princípio, de conceitos jurídicos indeterminados e de cláusulas-gerais. $O$ intérprete não cria os conteúdos, mas os (re)constrói.

Nos casos de interpretação operativa, a função interpretativa dos juízes e tribunais não é independente da função do legislador e das normas previstas na Constituição eclipsadas como direitos fundamentais, limites e vínculos para a decisão judicial, pois os juízes e tribunais, ao chegarem a uma decisão que reconstrua o ordenamento, passam, necessariamente, pela observância do princípio democrático, pela tradição jurídica e por uma premissa racional de universalização, que os vincula e vinculará todos os demais juízes e tribunais no momento futuro.

Não se pode falar em ofensa à legalidade, quando é a própria lei que estabelece a vinculatividade formal dos precedentes (art. 927). Obviamente, não haverá ofensa, desde que os precedentes formados respeitem à vinculatividade formal das leis, em uma relação circular (precedentes respeitam as normas legais e formam novas normas). Trata-se, portanto, de distinguir a função criativa do legislador da função interpretativa dos juízes e dos tribunais. Como é função dos juízes e tribunais interpretar os textos jurídicos e os textos não se confundem com normas (porque todo texto depende de interpretação e a norma é o resultado do texto interpretado), não há ofensa ao princípio da separação de poderes, quando o juiz ou tribunal aplicar a norma decorrente da interpretação dos textos legais, esta é a sua função. Ofensa haverá, entretanto, quando cada tribunal ou cada juiz interpretar a norma de um jeito, a partir de critérios totalmente subjetivos - na expressão popular, dois pesos e duas medidas-.

Por outro lado, evidentemente, esta reconstrução não é tão ampla quanto aparece. A uma primeira vista, se a fidelidade à lei é um ideal irrealizável,

23 Só ocorre interpretação operativa se a atividade identifica um caráter dúbio no sentido da interpretação. Não são, portanto, quaisquer decisões que formarão os precedentes, precedentes são apenas as decisões que acrescem conteúdo ao ordenamento jurídico. FERRAJOLI, Luigi. «Interpretazione dottrinale e interpretazione operativa». In Rivista Internazionale di Filosofia del Diritto, Volume 1, 1966; pp. 290-304; esp. pp. 291 e 292; WRÓBLEWSKI, Jerzy. «Legal decision and its justification». Logique et Analyse n. ${ }^{\circ} 14$. Bruxelles: Centre National de Recherches de Logique, 1971; p. 412; p. 413; CHIASSONI, Pierluigi, "Codici interpretativi. Progetto di voce per un Vademecum giuridico». Analisi e Diritto. Volume 2002; p. 55-124, 2003, nota 14; p. 60; esp. 82. 
por certo isto não significa aceitar uma interpretação qualquer, desprovida de significado ou com significado absurdo, que seja unanimemente considerada pelos juristas e pela comunidade jurídica como errônea, equivocada, bizarra ou inaceitável. Contudo, como revela a doutrina, mesmo nestes casos, existe uma escolha do intérprete, mesmo que coagido pela opinião dos demais juristas, o intérprete exerce a reconstrução, excluindo os sentidos inválidos ${ }^{24}$.

Concluindo, os precedentes são subordinados à legislação. O princípio da legalidade é um limite à aplicação dos precedentes. Os precedentes somente podem contrariar a lei, quando a decisão afastar a lei por inconstitucionalidade. O papel dos juízes e tribunais é, muitas vezes, (re)construir o ordenamento jurídico, a partir do direito legislado e da Constituição, interpretando/ aplicando o direito (interpretação operativa). Quando há aplicação direta de lei ou precedente, sem necessidade interpretação operativa, não há se falar em força normativa dos precedentes, mas da força vinculante da própria lei ou do precedente anterior ${ }^{25}$.

\section{CONCLUSÃO}

Pelas razões expostas, seja em benefício da legalidade, seja em benefício de valores jusnaturalistas, negar normatividade ao art. 927 e incisos do CPC (Lei 13.105/2015), é continuar no paradigma do CPC de 1973.

24 «I noncognitivisti non si nascondono, infine, che vi sono certamente delle situazione in cui la scelta degli interprete "non può" che cadere su di un determinato significato, suscettibile di rilevazione: nel senso che ogni diversa interpretazione sarebbe (pressoché) unanimemente considerata, dagli operatori del diritto e dalla cultura giuridica esterna, come frutto di ignoranza, bizzarria, o inaccettabile arbitrio-sarebbe, in altre parole, oltremodo inopportuna, se non del tutto impraticabile. Per costoro, tuttavia, una scelta conformistica, imposta dalle circostanze, è pur sempre una scelta ("coactus interpres tamen voluit")». Cfr. CHIASSONI, Pierluigi. Tecnica dell'interpretazione giuridica; p. 145.

25 SCHAUER, Frederick. Playing by the rules. A philosophical examination of rule-based decisionmaking in law and in life. Oxford: Oxford University Press, 1991; seção 3.4. 